\title{
MEDOS AQUÁTICOS: UMA POÉTICA DO HORROR LÍQUIDO EM
}

\author{
H. P. LOVECRAFT
}

\author{
AQUATIC FEARS: A POETICS OF LIQUID HORROR IN H. P. LOVECRAFT
}

\author{
Marcos Lampert Varnieri ${ }^{1}$ \\ Heitor Tomé da Rosa Filho ${ }^{2}$ \\ Regina da Costa da Silveira ${ }^{3}$
}

\begin{abstract}
Resumo
A ambivalência simbólica da água se expressa já nos textos bíblicos, ora como regeneração, ora como calamidade. Símbolo cambiante em diferentes culturas, a água em suas variações de significado tem fornecido aos poetas a trama para suas produções literárias. É o caso de García Lorca, com o tema da esterilidade em sua conhecida tragédia Yerma; da produção de Edgar Allan Poe, em que a água exemplifica o lado maléfico, de acordo com Gaston Bachelard. Tal é o sentido desse elemento na obra de H. P. Lovecraft: como água parada ou água morta, exalta-se aí o seu caráter devastador da água, nega-se, portanto, a vida, a força. Neste trabalho, identifica-se a influência da materialidade aquática na composição dos contos Dagon, What the Moon Brings, The Colour out of Space, The Shadow over Innsmouth e The Call of Cthulhu. O método orientador das reflexões aqui apresentadas pode ser visto como temático, conforme definição de Bergez (2006). O estudo das imagens ligadas à água contribui para expandir a leitura e o entendimento da obra de Lovecraft, comumente interpretada como terror cósmico.
\end{abstract}

Palavras-chave: imagens aquáticas, horror líquido, Lovecraft, Bachelard.

\begin{abstract}
Water appears in the work of H. P. Lovecraft not in its life-generating character, but in its inverse, that is, as still water or dead water that the theorist of literature Gaston Bachelard identifies in the work of another icon of the supernatural literature Edgar Allan Poe. This paper identifies the influence of aquatic materiality on the composition of the tales Dagon, What the Moon Brings, The Colour out of Space, The Shadow over Innsmouth and The Call of Cthulhu. The guiding method of the reflections presented here is called thematic according to Bergez (2006). The study of water-related images helps to expand the understanding of Lovecraft's work, commonly interpreted as cosmic terror.
\end{abstract}

Keywords: aquatic images, Lovecraft, Bachelard.

\footnotetext{
${ }^{1}$ Mestrando em Letras na UniRitter. Graduado em Licenciatura em Língua Inglesa e Literaturas de Língua Inglesa (UniRitter).

${ }^{2}$ Médico formado pela Universidade Federal do Rio Grande do Sul (UFRGS).

${ }^{3}$ Doutorado em Letras pela Universidade Federal do Rio Grande do Sul (UFRGS); Pós-doutorado na Universidade Federal do Rio de Janeiro (UFRJ), junto ao Programa de Pós-graduação em Ciência da Literatura (2017).
} 
Medos aquáticos: uma poética do horror líquido em H. P. Lovecraft

\section{Introdução}

A obra de H. P. Lovecraft (1890 - 1937) apresenta formas de horror que diferem dos monstros tradicionais da cultura literária. Não há vampiros ou lobisomens, mas figuras inspiradas no mar e no espaço extraterrestre, de onde a alcunha de terror cósmico para a sua ficção. Suas criaturas são, antes de tudo, indiferentes aos humanos. São deuses ou entidades de tempos imemoriais. Em muitos casos, não há sequer direto contato entre o personagem humano e o sobrenatural. Há, sim, uma visão de coisas impossíveis, que comumente deixam os personagens para sempre marcados pela loucura. Os deuses não se importam com os vivos; são o que são, existem por si e para si mesmos. Eventualmente podem destruir ou matar, porém isso não os define minimamente. Eles lá estavam muito aquém dos viventes e para além estarão depois de todos os mortais.

A ficção de Lovecraft compreende cerca de setenta contos e apenas três narrativas longas. Muitos de seus textos foram publicados na revista Weird Tales, lançada em 1923 e dedicada à literatura de fantasia e de horror. Apesar de publicado, não obteve reconhecimento em vida, fato muito diverso da atual apreciação de sua obra. Autores, cineastas, críticos e filósofos como Michel Houellebecq, Guillermo del Toro, S. T. Joshi e Graham Harman a tomam como fundamental para os estudos do fantástico e do estranho. O biógrafo S. T. Joshi observa, em texto introdutório à ficção completa, o fato de Lovecraft ser celebrado tanto pela crítica quanto pela cultura pop, pois seus personagens frequentam tanto as prestigiosas edições da Penguin Classics e da Library of America, quanto filmes e jogos digitais.

A apreciação crítica da obra lovecraftiana tende a ocupar-se do aspecto cósmico de suas criaturas, pois foi pioneiro na ficção científica associada ao terror. O intuito deste artigo, no entanto, é ressaltar a influência de um elemento caro à tradição poética, a saber, a imagética da água. Para tal, o trabalho de Gaston Bachelard fornece os elementos analíticos. A água desponta na obra de Lovecraft não em seu caráter gerador de vida, mas no seu inverso. São águas paradas, águas mortas, que o teórico francês já reconhecera nos textos de Edgar Allan Poe. Diante de uma imagética da finitude e da inquietante sensação dela advinda, é apropriado retomar a ficção de Lovecraft dentro da concepção do fantástico, pois, segundo Sigmund Freud, o inquietante (Unheimlich) ajuda a elucidar emoções arrebatadoras como a angústia e o medo, onipresentes na literatura fantástica. 
Medos aquáticos: uma poética do horror líquido em H. P. Lovecraft

O método deste artigo é temático, inspirado em Bachelard. Trata-se da seleção de imagens aquáticas, próprias à imaginação material em diferentes contos de H.P. Lovecraft. A imagética elementar fornece o ponto de comparação e compreensão dos textos, pois em cada umas das obras analisadas há a recorrência de uma substância, a água, dotada de um significado crucial e constante. Os contos aqui tratados são Dagon, What the Moon Brings, The Colour out of Space, The Shadow over Innsmouth e The Call of Cthulhu.

\section{Bachelard e o método temático}

A contribuição de Bachelard ao pensamento estende-se a ramos diversos das ciências e das artes, abordando temas aparentemente dispersos. Vincent Bontemps, em seu livro sobre o autor, identifica uma unidade no pensamento de Bachelard, a qual “[...] consiste em sua compreensão dinâmica dos progressos do espírito, esforçando-nos para isolar as invariantes das variações de suas reflexões sobre ciência, sobre a filosofia, assim como sobre a imaginação e o tempo.” (Bontemps, 2017, p. 34). Em suas obras iniciais, Bachelard dedicou-se à epistemologia da ciência, como em La formation de l'esprit scientifique (1938). Diante das limitações impostas pela Segunda Guerra Mundial, termina por dedicar-se às representações presentes na poesia. Bachelard distingue-se, portanto, ao transitar por saberes tradicionalmente distantes, verificando pontos de contato entre os campos.

A teoria de quatro elementos clássicos proposta por Empédocles é retomada por Bachelard como inspiração para compreender diversos textos literários, em seus ensaios sobre a imaginação da matéria. $\mathrm{O}$ fogo, o ar, a água e a terra são os elementos materiais que compõem não apenas os objetos, mas as próprias artístico-metafóricas. Diz Bachelard : "En effet, nous croyons possible de fixer, dans le règne de l'imagination, une loi des quatre éléments qui classe les diverses imaginations matérielles suivant qu'elles s'attachent au feu, à l'air, à l'eau, ou à la terre." (De fato, acreditamos ser possível fixar, no reino da imaginação, uma lei dos quatro elementos que classificam as várias imaginações materiais de acordo com o fato de se ligarem ao fogo, ar, água ou a terra.) (2015, p. 10). Sendo assim, o autor delimita suas obras aplicando tais elementos em La psychanalyse du feu (1938), em L'air et les songes (1943), em L'eau et les rêves (1942) e em La terre et les rêveries de la volonté (1948). Nas palavras de Bontemps, a presença desses elementos induz ao seu reconhecimento como operadores poéticos: 
Medos aquáticos: uma poética do horror líquido em H. P. Lovecraft

Certas imagens liberam as substâncias do mundo: são ditas elementares. Elas o são em três sentidos: enquanto primitivas; enquanto tiram sua substância de um elemento material; por fim, por serem o elemento no qual evolui a consciência do sonhador e do qual ele desposa o movimento. Elas são insistentes, tão profundas e universais que parecem pertencer tanto ao mundo natural quanto à natureza humana. (BONTEMPS, 2017, p. 132, grifos do autor)

Tal materialidade é o que dá suporte às imagens da poesia. Um dos autores privilegiados por Bachelard é Edgar Allan Poe, em cuja obra predomina o elemento aquático, na forma de “águas dormentes”. Paradas, essas águas assumem igualmente um aspecto escuro. A passagem seguinte ilustra a apreciação bachelardiana da obra do escritor gótico americano:

Na obra de muitos poetas aparece também o mar imaginário, que tomou assim a Noite no seu seio. É o Mar das Trevas - Mare tenebrarum, onde os antigos navegadores localizaram o seu assombro, mais do que sua experiência. A imaginação poética de Edgar Poe explorou esse mar das trevas. Frequentemente, sem dúvida, é o obscurecimento do céu em tempestade que dá ao mar suas tonalidades lívidas e negras. (BACHELARD, 2015, p. 119) ${ }^{4}$

Da mesma forma, a materialidade poética permite a Bachelard dispor autores conforme seu elemento predominante. Acompanhando Poe em imagens aquáticas, aparecem Paul Claudel, Gabriele D’Annunzio e Claude Monet. Alinhados no elemento ar, há Percy Shelley, Rainer Rilke e Marc Chagall. Friedrich Nietzsche, Friedrich Hölderlin e Novalis têm suas obras inspiradas pelo fogo, enquanto Victor Hugo, Johann von Goethe e Henri de Régnier são marcadamente terrestres. A sistematização dos quatro elementos, assim, fornece a Bachelard “[...] um plano cômodo para expor diferentes maneiras figuradas de viver as emoções." (BONTEMPS, 2017, p. 135, grifos do autor).

A riqueza das percepções de Bachelard quando trata da ficção literária estimulam intepretações também fecundas por parte de outros pensadores. Daniel Bergez (2006), ao

\footnotetext{
${ }^{4}$ Chez plusieurs poètes apparaît aussi une mer imaginaire qui a pris ainsi la Nuit dans son sein. C'est la Mer des Ténèbres - Mare tenebrarum, où les anciens navigateurs ont localisé leur effroi plutôt que leur expérience. L'imagination poétique d'Edgar Poe a exploré cette Mer des Ténèbres. Souvent, sans doute, c'est l'obscurcissement du Ciel en tempête qui donne à la mer ces teintes livides et noires.
} 
Medos aquáticos: uma poética do horror líquido em H. P. Lovecraft

refletir sobre métodos de análise literária, reúne sob o termo de crítica temática influenciada por Bachelard os seguintes autores: Georges Poulet, Jean Rousset, Jean Starobinski e JeanPierre Richard. Sob o conceito de tema, tomado como um índice, está reunido o ponto de compreensão e de comparação entre obras e autores. Bergez expande a reflexão quanto ao uso da noção temática para os estudos literários ao explicar que:

A crítica temática é, com efeito, ideologicamente filha do Romantismo. Entretanto, a referência aos "temas" nos estudos literários é bem anterior. O termo é herdado da antiga retórica, que concedia grande importância ao "topos", elemento de significação determinante num dado texto. (BERGEZ, 2006, p. 99).

Uma vez identificado um tema em certa obra, é possível generalizar a descoberta com o auxílio de complexos. Para o tema aquático, Bachelard se vale dos complexos de Caronte, de Ofélia e de Swinburne. Caronte remete à travessia de águas mortas e ao luto restante aos que ainda não se foram. Ofélia evoca a morte e a morbidez do afogamento, da loucura e da solidão. Já Swinburne assume a dimensão masoquista do flagelo das águas. Prossegue Bergez sobre o método: "A leitura temática das obras em geral se organiza, pois, em função das categorias da percepção e da relação: tempo, espaço, sensações..." (2006, p. 106).

A aplicação do método temático à obra de Lovecraft permite, pois, reconhecer o tema aquático como um dos núcleos de sentido de suas narrativas. A água escura e mortal, tal como na obra de Poe, está presente nos contos aqui analisados. A análise ora proposta segue o mesmo espírito bachelardiano:

A fim de desembaraçar essa "participação" que é a própria essência do pensamento das águas, do psiquismo hídrico, precisaremos nos debruçar sobre exemplos muito raros. Mas se pudermos convencer nosso leitor de que há, sob as imagens superficiais da água, uma série de imagens cada vez mais profundas, cada vez mais tenazes, ele logo estará experimentando, em suas próprias contemplações, uma simpatia por esse aprofundamento; ele sentirá se abrir, sob a imaginação das formas, a imaginação das substâncias. (BACHELARD, 2015, p. 12)

\footnotetext{
${ }^{5}$ Pour bien dégager cette "participation" qui est l'essence même de la pensée des eaux, du psychisme hydrant, nous aurons donc besoin de nous appesantir sur des exemples trop rares. Mais si nous pouvons convaincre notre lecteur qu'il y a, sous les images superficielles de l'eau, une série d'images de plus en plus profondes, de plus en plus tenaces, il ne tardera pas à éprouver, dans ses propres contemplations, une sympathie pour cet approfondissement ; il sentira s'ouvrir, sous l'imagination des formes, l'imagination des substances. (BACHELARD, 2015, p. 12)
} 
Medos aquáticos: uma poética do horror líquido em H. P. Lovecraft

Pela investigação das formas aquáticas de cada narrativa, chegar-se-á à profundidade criativa de Lovecraft em seu horror marítimo, observando-se como cada conto participa do tema da água e o aprofunda sob a forma da morte e do medo.

\section{3. Águas mortais}

O celebrado horror cósmico de Lovecraft é por ele mesmo explicado em uma carta: "Now all my tales are based on the fundamental premise that common human laws and interests and emotions have no validity or significance in the vast cosmos-at-large." (Agora todos os meus contos são baseados na premissa fundamental de que as leis, interesses e emoções humanos comuns não têm validade ou significado no vasto cosmo como um todo). (LOVECRAFT, 1965-76 apud Joshi, 2004, p. 77). O autor explica que o efeito de medo que busca em suas obras está na insignificância do humano perante a magnitude do universo.

Não obstante o aspecto do terror lovecraftiano ter sido recorrente entre a crítica de suas narrativas, outra vertente se abre para a compreensão da obra de Lovecraft. Trata-se de uma análise da criação poética que passe a considerar o elemento aquático como inspirador da imaginação. Nessa direção, é possível observar que a água serviu à literatura como tema em diferentes gêneros e obras. Ora aparece como lagos, córregos ou fontes que invocam a poesia lírica ou pastoral em toda a sua tranquilidade, ora vem como aventura marítima por obra de piratas e pescadores, dando ênfase ao movimento. Segundo Bachelard, há forças da imaginação que penetram o fundo do ser, "elles veulent trouver dans l'être, à la fois, la primitif et l'éternel." (Eles querem encontrar no ser, ao mesmo tempo, o primitivo e o eterno). (BACHELARD, 2015, p. 7). Ora, o primitivo e o eterno são corporificados nas criaturas de Lovecraft que comumente saem das águas oceânicas. Dagon e Cthulhu são divindades monstruosas emergidas de pélagos insondáveis. O que escapa ao entendimento ganha figura em uma criação poética que corporifica o assombroso com a fluidez das substâncias coloidais. A água é ainda normalmente associada ao elemento feminino, à maternidade, porém Bachelard indica que ela pode mudar de sexo. Em sua personificação masculina, o aquático indica a violência, a cólera, o mal e o 
Medos aquáticos: uma poética do horror líquido em H. P. Lovecraft

rancor. Os deuses lovecraftianos, embora sem possuir necessariamente uma tendência maligna, têm formas associadas com o sombrio, com a noite e com demônios das religiões humanas.

O conto Dagon (publicado em 1923 na revista Weird Tales) relata o espanto de um comerciante marítimo ao acordar em um pântano negro após ter escapado de ladrões que atacaram sua embarcação e haver navegado por dias no Oceano Pacífico. Sobre o espaço que o circunda, diz o personagem: "The region was putrid with carcasses of decaying fish, and of other less describable things which I saw protruding from the nasty mud of the unending plain. [...] nothing in sight save a vast reach of black slime.” (A região era pútrida com carcaças de peixes decompostos e outras coisas indescritíveis que vi emergindo da lama nojenta de uma planície infindável). (LOVECRAFT, 2011, p. 24, tradução nossa) ${ }^{6}$. O personagem supõe que um vulcão submarino tenha causado a elevação desse estranho pântano. Investigando o estranho local, ele encontra um abismo negro aparentemente sem fundo e próximo a este um monolito de proporções ciclópicas. O monumento está coberto de hieróglifos de figuras marinhas e apresenta seres humanoides com traços písceos. A próxima visão será aquela que deixara o personagem dependente de morfina até seus últimos dias. É o próprio deus marinho da tradição filisteia Dagon que aparece junto ao monolito. Na Bíblia, em Juízes 16, 23 lê-se: “Os príncipes dos filisteus reuniram-se para oferecer um grande sacrifício a Dagon, seu deus, e para se entregarem às comemorações". A loucura se instala no narrador e ele mal pode relembrar como retornou à civilização. Agora é contemplando a lua, a mesma que iluminou suas visões terríveis no lodo do Pacífico, que o personagem teme um novo encontro com tais entes das profundezas. Seu suicídio subsequente é indicado pelas exclamações: "It shall not find me. God, that hand! The window! The window! (Ele não me encontrará. Deus, aquela mão! A janela! A janela!) (p. 27 , grifos do autor). Basta a visão do abismo e do colosso para diluir a sanidade do personagem.

A divindade anfíbia Dagon retorna na obra The Shadow over Innsmouth (A sombra sobre Innsmouth), publicada em 1936. O narrador personagem Robert Olmstead conta como foi sua passagem pela decrépita cidade pesqueira de Innsmouth. A aparência dos moradores da localidade logo chama a atenção, pois, como será revelado no decorrer da história, houve um cruzamento entre os humanos da cidade e uma raça de seres marinhos. O culto a Dagon e seus

\footnotetext{
${ }^{6}$ As traduções usadas neste artigo são nossas, e as referências da obra de Lovecraft serão indicadas apenas por números conforme H. P. Lovecraft: the complete fiction (2011).
} 
Medos aquáticos: uma poética do horror líquido em H. P. Lovecraft

“filhos" aquáticos, os Deep Ones (os das profundezas), é organizado pela Esoteric Order of Dagon (Ordem Esotérica de Dagon) que oferece sacrifícios aos seus senhores marinhos. Acerca da arte associada a tais seres anfíbios, o narrador diz:

Todos os padrões sugeriam segredos remotos e abismos inimagináveis no tempo e no espaço, e a natureza monotonamente aquática dos relevos tornouse quase sinistra. Entre esses relevos estavam monstros fabulosos de malignidades repugnantes e grotescas - metade ictíico e metade batráquio que não se podia dissociar de uma certa sensação desconcertante e assombrosa de pseudomemória, como se invocassem alguma imagem de células e tecidos profundos cujas funções retentivas são totalmente primevas e incrivelmente ancestrais. Às vezes eu imaginava que todos os contornos dessas sapos-peixes blasfemos estavam transbordando com a quintessência última de um mal desconhecido e desumano. (p. 814, tradução nossa) ${ }^{7}$

O conto prossegue com a fuga do protagonista após uma perseguição pelas ruas da cidade amaldiçoada por entidades aquáticas de tal natureza sombria. O desfecho se dá pela ação das forças da ordem na cidade, alertadas por Olmstead.

No poema em prosa What the Moon Brings (O que a lua traz), publicado em 1923 no National Amateur, as imagens da água estão intimamente ligadas às da Lua. O narrador anuncia logo de início o seu ódio à Lua: "I hate the Moon - I am afraid of it - for when it shines on certain scenes familiar and loved it sometimes makes them unfamiliar and hideous" (p. 212). Tal concepção é identificável à de Sigmund Freud em seu ensaio sobre o estranho ou o inquietante, Das Unheimlich, de 1919. A luz da Lua transforma o conhecido em seu contrário. Esse efeito de transformação do conhecido em desconhecido é uma das características centrais do conceito freudiano, pois "[...] o inquietante é aquela espécie de coisa assustadora que remonta ao que é a muito conhecido, ao bastante familiar.” (FREUD, 2010, p. 331).

Segue o narrador, passeando por um jardim em noite enluarada, comentando sobre as imagens que o córrego ali presente lhe provoca: "those moon-cursed waters" (essas águas amaldiçoadas pela lua) (p. 212) evocam uma calma mortal "sinistre resignation of calm, dead

\footnotetext{
7 The patterns all hinted of remote secrets and unimaginable abysses in time and space, and the monotonously aquatic nature of the reliefs became almost sinister. Among these reliefs were fabulous monsters of abhorrent grotesqueness and malignity - half ichthyic and half batrachian in suggestion - which one could not dissociate from a certain haunting and uncomfortable sense of pseudomemory, as if they called up some image from deep cells and tissues whose retentive functions are wholly primal and awesomely ancestral. At times I fancied that every contour of these blasphemous fish-frogs was over-flowing with the ultimate quintessence of unknown and inhuman evil. (p. 814)
} 
Medos aquáticos: uma poética do horror líquido em H. P. Lovecraft

faces" (resignação sinistra de faces mortas e calmas), faces mortas vistas nas flores de lótus levadas pela correnteza (p. 212). O córrego, na inspiração imagética do narrador, passa a ser um rio fluindo entre pântanos e chega a um mar sem nome, um "nameless sea” (mar inominado) (p. 212). Nesse mar mortífero, uma cidade coberta de algas é percebida como o lar dos falecidos. Tanto é assim, que o narrador imagina um condor junto às ruínas que poderia lhe responder sobre os que já partiram desta vida. Repete-se nessa obra a visão de uma gigantesca forma, desta vez não de um mostro, mas de uma estátua descomunal coberta de recifes e criaturas marinhas. A narrativa não termina em tragédia, mas na fuga por entre os vermes marinhos que devoram toda a vida.

O conto The Colour out of Space (A cor que caiu do espaço), publicado em 1927 na revista Amazing Stories, é ambientado em cenário rural, e para lá um meteorito conduz algo sinistro. A criatura, personagem do conto, também tem forma coloidal, apresentando glóbulos coloridos. O ser não tem figura definida e acaba por consumir a matéria orgânica que toca. Ainda sobre a criatura é dito que permanece "malignly bubbling in its cosmic and unrecognizable chromaticism" (borbulhando malignamente em seu cromatismo cósmico e irreconhecível) (p. 614). É interessante notar que o refúgio de tal criatura-cor é o poço da velha fazenda. Também esse ser espacial busca a água como abrigo. Os membros da família moradora da estância perecem um a um, quando do encontro com tal luz gelatinosa. Só o que resta é uma área devastada após e ejeção da criatura rumo ao espaço, uma vez que acumulou energia suficiente ao devorar a vida circundante para retornar o seu caminho cósmico. O narrador afirma sobre o tal ser: "It was just a colour out of space - a frightful messenger from unformed realms of infinity beyond all Nature as we know it; from realms whose mere existence stuns the brain and numbs us with the black extra-cosmic gulfs it throws open before our frenzied eyes." (Era apenas uma cor fora do espaço - um mensageiro assustador de reinos desformes do infinito além de toda a Natureza como a conhecemos; de reinos cuja mera existência atordoa o cérebro e nos entorpece com os abismos extracósmicos negros que ele abre diante de nossos olhos frenéticos.) (p. 616).

A materialidade aquática explorada por Bachelard está plenamente presente nessas obras. A água é para o teórico da poesia um espelho que ora reflete a vida ora a morte. "L’eau en sa jeune limpidité est un ciel renversé où les astres prennent une vie nouvelle.” (A água em sua jovem limpidez é um céu invertido, onde os astros tomam uma nova vida) (BACHELARD, 
Medos aquáticos: uma poética do horror líquido em H. P. Lovecraft

2015, p. 60). É desse modo que ele interpreta a obra de Edgar Allan Poe, na qual a água espelha o céu em certos poemas. Entretanto, é na água sombria e noturna que o fantástico e o assustador de Poe podem encontrar as profundezas de Lovecraft. O oceano de Dagon e Cthulhu espelha o vazio cósmico do espaço exterior.

Ao tratar das águas, Bachelard não deixa de mencionar as imagens sobre o fluxo e o devir do rio heraclitiano. Uma consulta à obra de Giovanni Reale (2005) sobre os pré-socráticos, no capítulo sobre o filósofo Heráclito, evidencia justamente o aspecto aquático como o motivo da loucura: "Por um lado, ele, como os milesianos, identificou a natureza da alma com a natureza do princípio e disse que é fogo, e também disse ser mais sábia a alma mais seca, e, por consequência, fez coincidir a perda do senso com o umedecimento da alma.” (Reale, 2005, p. 70). Eis pois, uma justificação para a loucura dos personagens de Lovecraft ao se depararem com tais monstros úmidos. Suas almas se tornam aquosas, seu fogo interior se extingue.

\section{Um monstro para todos governar}

O conto The Call of Cthulhu (O Chamado de Cthulhu) relata diversas manifestações na imaginação humana, ora religiosa ora artística, acerca dos seres antigos, "The Old Ones" (Os antigos). "The great priest Cthulhu" (O grande sacerdote Cthulhu) é a presença constante nos sonhos de vários cultos obscuros e de artistas sensíveis ao seu chamado. As vozes dos deuses em estado de hibernação se manifestam nos sonhos das criaturas materiais. "When, after infinities of chaos, the first men came, the Great Old Ones spoke to the sensitive among them by molding their dreams, for only thus could Their language reach the fleshly minds of mammals." (Quando, depois de infinidades de caos, chegaram os primeiros homens, os Grandes Antigos falaram aos sensíveis dentre eles, moldando seus sonhos, pois só assim sua linguagem poderia chegar às mentes carnais dos mamíferos) (p. 367).

Um dos personagens na narrativa é o jovem artista Henry Anthony Wilcox que esculpe a forma cefalópode da criatura. Já está aí a referência marinha, pois o grande profeta dos seres antigos tem a cabeça semelhante a de um polvo. O relato prossegue com o encontro de estátuas e baixos-relevos, figurando o ser adormecido sob o oceano Pacífico. O relato mais contundente é o de um marinheiro norueguês Gustaf Johansen, que teve um contato direto com Cthulhu. Após peripécias no mar envolvendo um ataque ao navio onde trabalhava, Gustaf acaba 
Medos aquáticos: uma poética do horror líquido em H. P. Lovecraft

encontrando junto com os membros da tripulação uma estranha cidade. R'lyeh é o nome de tal lugar, onde repousam os seres antigos. Nessa cidade de dimensões ciclópicas, a geometria e o espaço confundem os exploradores, pois não há como definir o que está na posição horizontal ou na vertical. É dito que a geometria do lugar é não euclidiana, ou seja, possui dimensões não apreensíveis. Entretanto, não é a espacialidade estupefaciente o aspecto mais terrível. Ao conseguirem abrir uma porta gigantesca, os marinheiros incautos acordam o grande profeta. Cthulhu logo arrebata alguns dos homens deste mundo e parte em perseguição aos demais. De volta ao barco e em fuga o medo os consome, pois veem que o gelatinoso ser os persegue em alto mar. Um dos marinheiros chamado William Briden sucumbe à loucura ao contemplar Cthulhu, enquanto Gustaf, em ato desesperado, temendo não escapar do monstro, vira o barco e navega a toda velocidade contra a cabeça do inimigo. A cabeça sendo gelatinosa se abre, permitindo a Gustaf escapar, mas ele ainda pôde ver a regeneração ocorrendo. Após o fato, a memória do marinheiro à semelhança de seu companheiro decai em confusão. Ele é, por fim, resgatado com vida por outra embarcação e termina seus poucos dias restantes em Oslo, onde compõe, como último testemunho, um diário narrando o encontro terrível.

Cthulhu é o ser que sintetiza o tipo de monstro lovecraftiano, uma vez que é gigantesco, marítimo, incompreensível e, quando não mata diretamente os humanos que o encontram, levaos à insanidade. A imagem oceânica é própria do monstro, pois o mar tem a dimensão do espaço descomedido e reflete a impotência da vontade humana diante do poder das vagas. A tradição literária muito usou do habitat marinho para situar monstros terríveis. Caríbdis e Cila são monstros marinhos da poética grega que põem Odisseu à prova, bem como as sereias, que à semelhança de Dagon, híbrido masculino, combinam o feminino e o terrível. Mesmo o mundo dos mortos é bordejado pela água. Somente com o transporte feito por Caronte, o barqueiro "sombrio", podem os mortos entrar no Orco, correspondente ao Averno latino e ao grego Hades. Para Bachelard: “En lisant Poe, on comprend plus intimement l'étrange vie des eaux mortes et le langage apprend la plus terrible des syntaxes, la syntaxe des choses qui meurent, la vie mourante." (Ao ler Poe, entende-se mais intimamente a vida estranha das marés e a língua aprende a mais terrível das sintaxes, a sintaxe das coisas que morrem, a vida morrendo.) (BACHELARD, 2015, p. 20). Claro está que em Lovecraft também a sintaxe da morte se dá na forma e no conteúdo de seus textos. 
Medos aquáticos: uma poética do horror líquido em H. P. Lovecraft

\section{Conclusão}

A validade de um método temático se afirma pela possibilidade de selecionar imagens e temas recorrentes em obras distintas, pois, uma vez identificado o ponto comum, é possível compreender o efeito estético presente em cada uma delas. A alquimia poética bachelardiana fornece um complexo de termos próprios à interpretação do literário pela ênfase em um elemento basal predominante. Para um autor como H. P. Lovecraft, tal método concede à obra verdadeiros nós interpretativos que mantêm a riqueza imagética evocada por cada conto.

Quanto à análise de Bachelard acerca de Edgar Allan Poe, ela é precisa ao identificar a materialidade das águas mortas. Na ficção de Lovecraft, cujas personagens eram inspiradas no mar e no espaço exterior à Terra, pode-se afirmar que a alcunha de terror cósmico é por demais apropriada. Suas criaturas são, antes de tudo, indiferentes aos humanos porque fogem aos padrões considerados normais num mundo que precisa sobremaneira da purificação das águas para sua própria sobrevivência. Nessa direção, o humano é o monstro das águas: emergindo da pureza dos rios, as águas tornaram-se miseravelmente parcas e turvas graças à ação do homem. Espelhar-se nas águas turvas é se ver na imagem do terror e da monstruosidade que habita o ser. Nas águas mortas, as coisas são vistas como inacreditáveis e impossíveis. Não por acaso, parte da epígrafe de Algernon Blackwood, em O Chamado de Cthulhu, reafirma que

De tais grandes poderes ou seres, pode haver uma sobrevivência concebível. . . uma sobrevivência de um período extremamente remoto quando. . . a consciência se manifestou, talvez, em formas e figuras há muito anteriores à maré da humanidade vindoura. . . formas das quais a poesia e a lenda sozinhas captaram uma memória passageira e as chamaram deuses, monstros, seres míticos de todos os tipos e tipos... (p. 355, tradução nossa). ${ }^{8}$

Assim, ver-se diante do monstro é estranho e ao mesmo tempo familiar na ficção lovecraftiana, suspeita-se por isso mesmo que seja comum entre seus personagens tornarem-se quase sempre marcados pela loucura.

\footnotetext{
8 "Of such great powers or beings there may be conceivably a survival . . . a survival of a hugely remote period when . . . consciousness was manifested, perhaps, in shapes and forms long since withdrawn before the tide of advancing humanity ... forms of which poetry and legend alone have caught a flying memory and called them gods, monsters, mythical beings of all sorts and kinds...” (p. 355)
} 
Medos aquáticos: uma poética do horror líquido em H. P. Lovecraft

Com a atenção dada às imagens aquáticas na obra de H. P. Lovecraft, é possível expandir a compreensão de suas narrativas. O terror cósmico predomina, mas não é a sua única fonte de inspiração criativa. As águas profundas e escuras são o outro espaço privilegiado para dar forma aos Great Old Ones (Grandes Antigos).

\section{Referências}

BACHELARD, G. L'eau et les rêves. Paris. Le Livre de Poche, 2015.

BERGEZ, D. et al. Métodos críticos para a análise literária. Tradução: Olinda Maria Rodrigues Prata. São Paulo: Martins Fontes, 2006.

BONTEMPS, V. Bachelard. Tradução: Nícia Adan Bonatti. São Paulo: Estação Liberdade, 2017.

FREUD, S. Obras completas, volume 14: História de uma neurose infantil ("O homem dos lobos"); Além do princípio do prazer e outros textos (1917 - 1920). Tradução: Paulo César de Souza. São Paulo: Companhia das Letras, 2010.

JOSHI, S. T. The evolution of the weird tale. New York: Hippocampus Press, 2004.

JUÍZES. In: Bíblia de Jerusalém. São Paulo: Paulus, 2013.

LOVECRAFT, H. P. H. P. Lovecraft: The complete fiction. New York: Barnes \& Noble, 2011.

REALE, G. História da filosofia antiga: volume 1. São Paulo: Loyola, 2005.

Artigo recebido em: 02/08/2018

Artigo aceito para publicar em: 19/09/2018 